University of South Florida

DIGITAL COMMONS

Digital Commons @ University of

@ UNIVERSITY OF SOUTH FLORIDA

South Florida

$1-2017$

\title{
Virtual Anastylosis of Greek Sculpture as Museum Policy for Public Outreach and Cognitive Accessibility
}

\author{
Filippo Stanco \\ University of Catania \\ Davide Tanasi \\ University of South Florida, dtanasi@usf.edu \\ Dario Allegra \\ University of Catania \\ Filippo L.M. Milotta \\ University of Catania \\ Gioconda Lamagna \\ Museo Archeologico Regionale "Paolo Orsi" di Siracusa
}

See next page for additional authors

Follow this and additional works at: https://digitalcommons.usf.edu/hty_facpub

\section{Scholar Commons Citation}

Stanco, Filippo; Tanasi, Davide; Allegra, Dario; Milotta, Filippo L.M.; Lamagna, Gioconda; and Monterosso, Giuseppina, "Virtual Anastylosis of Greek Sculpture as Museum Policy for Public Outreach and Cognitive Accessibility" (2017). History Faculty Publications. 8.

https://digitalcommons.usf.edu/hty_facpub/8

This Article is brought to you for free and open access by the History at Digital Commons @ University of South Florida. It has been accepted for inclusion in History Faculty Publications by an authorized administrator of Digital Commons@ @niversity of South Florida. For more information, please contact digitalcommons@usf.edu. 


\section{Authors}

Filippo Stanco, Davide Tanasi, Dario Allegra, Filippo L.M. Milotta, Gioconda Lamagna, and Giuseppina Monterosso 


\section{Electronnic Imaging}

\section{Virtual anastylosis of Greek sculpture as museum policy for public outreach and cognitive accessibility}

Filippo Stanco

Davide Tanasi

Dario Allegra

Filippo Luigi Maria Milotta

Gioconda Lamagna

Giuseppina Monterosso 


\title{
Virtual anastylosis of Greek sculpture as museum policy for public outreach and cognitive accessibility
}

\author{
Filippo Stanco, ${ }^{a, *}$ Davide Tanasi, ${ }^{\mathrm{b}}$ Dario Allegra, ${ }^{\mathrm{a}}$ Filippo Luigi Maria Milotta, ${ }^{\mathrm{a}}$ Gioconda Lamagna, ${ }^{\mathrm{c}}$ and \\ Giuseppina Monterossoc \\ aUniversity of Catania, Department of Mathematics and Computer Science, Viale A. Doria 6, 95125 Catania, Italy \\ bUniversity of South Florida, Center for Virtualization and Applied Spatial Technologies and Department of History, 4202 East Fowler Avenue, \\ Tampa, Florida 33620, United States \\ "Museo Archeologico Regionale "Paolo Orsi" di Siracusa, Viale Teocrito 66, 96100 Siracusa, Italy
}

\begin{abstract}
This paper deals with a virtual anastylosis of a Greek Archaic statue from ancient Sicily and the development of a public outreach protocol for those with visual impairment or cognitive disabilities through the application of three-dimensional (3-D) printing and haptic technology. The case study consists of the marble head from Leontinoi in southeastern Sicily, acquired in the 18th century and later kept in the collection of the Museum of Castello Ursino in Catania, and a marble torso, retrieved in 1904 and since then displayed in the Archaeological Museum of Siracusa. Due to similar stylistic features, the two pieces can be dated to the end of the sixth century $\mathrm{BC}$. Their association has been an open problem, largely debated by scholars, who have based their hypotheses on comparisons between pictures, but the reassembly of the two artifacts was never attempted. As a result the importance of such an artifact, which could be the only intact Archaic statue of a kouros ever found in Greek Sicily, has not fully been grasped by the public. Consequently, the curatorial dissemination of the knowledge related with such artifacts is purely based on photographic material. As a response to this scenario, the two objects have been 3-D scanned and virtually reassembled. The result has been shared digitally with the public via a web platform and, in order to include increased accessibility for the public with physical or cognitive disabilities, copies of the reassembled statue have been 3-D printed and an interactive test with the 3-D model has been carried out with a haptic device. () 2017 SPIE and IS\&T [DOI: 10.1117/1.JEI.26.1.011025]
\end{abstract}

Keywords: three-dimensional scanning; virtualization; virtual anastylosis; Greek sculpture; public outreach; haptic technology.

Paper 16607SS received Jul. 14, 2016; accepted for publication Dec. 13, 2016; published online Jan. 11, 2017.

\section{Introduction}

\subsection{Democratization of Cultural Heritage}

The fact that archaeological heritage, as a physical remnant of past and lost civilizations, has come to us after millennia and in good condition in many cases, despite all the forces that threatened it, does not allow us to take for granted that we will be able to pass it as it is to future generations. Never in the recent history of archaeology, whether it be artifacts or sites or landscapes, has the field been so endangered by old and new enemies.

The destructive force of nature has demonstrated time and time again how an entire site can be annihilated in a short lapse of time causing irreparable damage, especially in those countries rich in archaeology but poor in technical knowledge. A shocking example, which unfortunately did not have much coverage on the media, is represented by the complex of 1400 temples of the Shwedagon Pagoda (sixth to tenth century), in the Irrawaddy Delta region of Myanmar, which were razed to the ground by a cyclone in $2008 .{ }^{1}$

Notwithstanding, a natural disaster is not enough to raise public awareness of the transience of archaeological heritage. In fact, in our collective memory, there is still room to remember the devastations caused by terrorist groups in Afghanistan, Iraq, and Syria, which, in the last 15 years, destroyed world heritage sites and monuments of splendid

*Address all correspondence to: Filippo Stanco, E-mail: fstanco@dmi.unict.it civilizations spared by millennia, making archaeology another casualty of their madness. ${ }^{2}$

However, there are other threats that can condemn the archaeological heritage to oblivion without harming it physically or being criticized and publicly denounced. Wrong and short-sighted governmental decisions have sacrificed knowledge and public outreach on the altar of best practice in business and politics. ${ }^{3}$

An emblematic case is represented by the Roman statue known as Venus of Cyrene, ${ }^{4}$ dated to the second century AD. The sculpture was found in 1913 by Italian archaeologists in the sanctuary of Apollo at Cyrene, when Libya was an Italian colony, and subsequently delivered to Italy and kept in the Museum of the Baths of Diocletian at Rome. In 2008, in the framework of an economic agreement between the Italian and Libyan governments, Italy sent the Venus of Cyrene back to Libya. The delivery took place during a great ceremony at Bengasi, where the statue was presented before being sent to the Museum of Tripoli. The Venus of Cyrene never made it to the Museum of Tripoli and during the first civil war in 2011 the statue vanished. In this case, a political decision produced the same outcome as a bomb.

In certain countries with a rich past and an abundance of archaeological monuments, another plague is represented by the illegal excavations and international trafficking of archaeological artifacts, a phenomenon which in Italy, and especially in Sicily, is considered one of the emerging fields of interest

1017-9909/2017/\$25.00 @ 2017 SPIE and IS\&T 
of criminal organizations. "Archeomafia," as it is commonly called, endangers not just archaeological artifacts still buried in poorly defended sites or parks, but also those safe and sound in the collections of well-known museums. ${ }^{6}$

Virtualization and digital dissemination in such cases of endangered or inaccessible heritage have demonstrated themselves to be powerful methods of democratizing knowledge and reaching out to the public beyond any kind of geographical, linguistic, or cultural barriers. ${ }^{7}$

However, the production of digital replicas of ancient artifacts and the interaction with the three-dimensional (3-D) models, despite the trending role of virtual archaeology, ${ }^{8}$ is not always the best solution, especially when the dissemination process needs to be more participative and inclusive, as it is when it comes to people with visual impairments or cognitive disabilities. ${ }^{9}$

\subsection{Digital archaeology, Cognitive Accessibility, and Touch Interaction}

"The modern museum is all too frequently a site of reverence and silence, filled with people acting and feeling as if they were visiting their dead or moribund relatives." 10 This striking sentence from a seminal paper about museum accessibility perfectly summarizes the general attitude of the public toward visiting an archaeological museum. Such a repository of relics is entrusted to preserve them in perpetuity, but at the same time, it must make them accessible. The fear of deterioration often denies access or imposes limits on the interaction of visitors and artifacts. These limits are often related to tactile interaction.

The impossibility to touch an archaeological artifact does not just exclude visually impaired museum-goers from the cognitive experience, but also prevents a more in-depth and inclusive multisensory understanding of the object. The results of the research carried out in 2006 at the Northlight Gallery in Huddersfield (UK), a tactile exhibition interpreting the bronze bust of Sophocles from the British Museum's Greek and Roman Antiquities collection via visual arts, preventively 3-D scanned with a Faro Laser ScanArm, have demonstrated that the appeal of a tactile experience can enhance the learning process creating the illusion of a oneto-one interaction between visitor and object. ${ }^{11}$

Tactile interaction provides a further set of learning skills to the general public and supports more inclusive policies of public outreach for persons with visual impairments or cognitive disabilities. In this perspective, some recent works have pointed out the importance of 3-D digital imaging as a natural completion of touch interaction to achieve new levels of "cognitive accessibility.",12,13

The growing use of 3-D digital imaging techniques for the study and dissemination of archaeology, possibly destined to become an indispensable media through which interaction with ancient material culture, ${ }^{14}$ together with recent advances of haptic digital technologies, ${ }^{15}$ can certainly offer alternatives to museum curators caught in the cross-fire of preservation and accessibility.

Accessibility becomes a crucial issue when a museum, for historical or political reasons, cannot display certain artifacts because they have been stolen or permanently lent to other institutions.

In this case, 3-D digital imaging can "make visible the invisible" and virtually bring back the missing or lost objects. ${ }^{16}$
However, even in that case, no matter how powerful a 3-D model-interactive or not-can be, the absence of a tactile interaction still impedes reaching a higher level of learning through the object.

\section{Case Study: An Archaic Kouros From Leontinoi}

As a response to the scenario described above, this paper focuses on a problematic case study represented by two matching pieces of a statue kept in two different museums, the reputation of which can be restored via an exercise of virtual anastylosis. The research developed through five main steps: 3-D scanning of the two objects, virtual anastylosis (Sec. 3), creation of a web platform for public sharing (Sec. 4), 3-D printing of the reassembled statue, and learning experience via haptic devices (Sec. 5).

Greek Archaic sculpture is dominated by the production of statues of young naked boys, known as "kouroi" (plural of "kouros" meaning "boy" in Greek), and young girls with long dresses, named "korai" (plural of "kore" meaning "girl" in Greek), which have religious or funerary significance and for this reason are generally offered as ex-voto in sanctuaries or placed above or by tombs in cemeteries. ${ }^{17}$

The statues were the symbolic representation of the worshippers consecrating their lives to the deities or idealized portraits of the dead.

Their widespread distribution in the Greek Mediterranean between the end of seventh and the early decades of the fifth century BC testifies to the popularity of these iconographies that summarized the concept of "kalokagathia," the combination of virtues-goodness and excellence-to which Greek civilization was devoted. ${ }^{18}$

In Greek Sicily, there are several remarkable examples of kouroi and korai imported from Greece or locally produced, and some of them can certainly be considered as masterpieces of Greek statuary. ${ }^{19}$

However, very few life-size statues were found intact. After the Classical period, it became customary to detach the heads of Greek statues in order to create head-portraits. In fact, with a few exceptions of smaller scale statues found intact, this class of Greek statues in Sicily is represented just by heads without matching bodies and headless bodies.

A unique case is that of the "Biscari head" kept at the Museo Civico "Castello Ursino" di Catania and of the torso from Leontinoi in display at the Regional Archaeological Museum "Paolo Orsi" of Siracusa, both made of marble, dated between the end of sixth and beginning of fifth century $\mathrm{BC}$ and almost unanimously believed to be part of the same life-size kouros. ${ }^{20}$

The head was part of the private collection of Ignazio Paternò Castello, fifth Prince of Biscari (1719 to 1786), the founding figure of early archaeological research and antiquarianism in 18 th century Sicily. ${ }^{21}$ The head, also known as the Biscari head, recovered in the site of the Greek city of Leontinoi, was exhibited for a long time in the Hall of Marbles of the Museum of Palazzo Biscari alla Marina (Fig. 1) before being incorporated in the main collection of the Museo Civico "Castello Ursino" of Catania. ${ }^{22,23}$ In a rare picture taken around 1938 from the archive of Fratelli Alinari (Fig. 2), the head appears set on a gypsum base attached to a wooden pedestal, which was later removed.

The torso (Fig. 3) was accidentally found in the country right outside the area of the ancient colony of Leontinoi and 


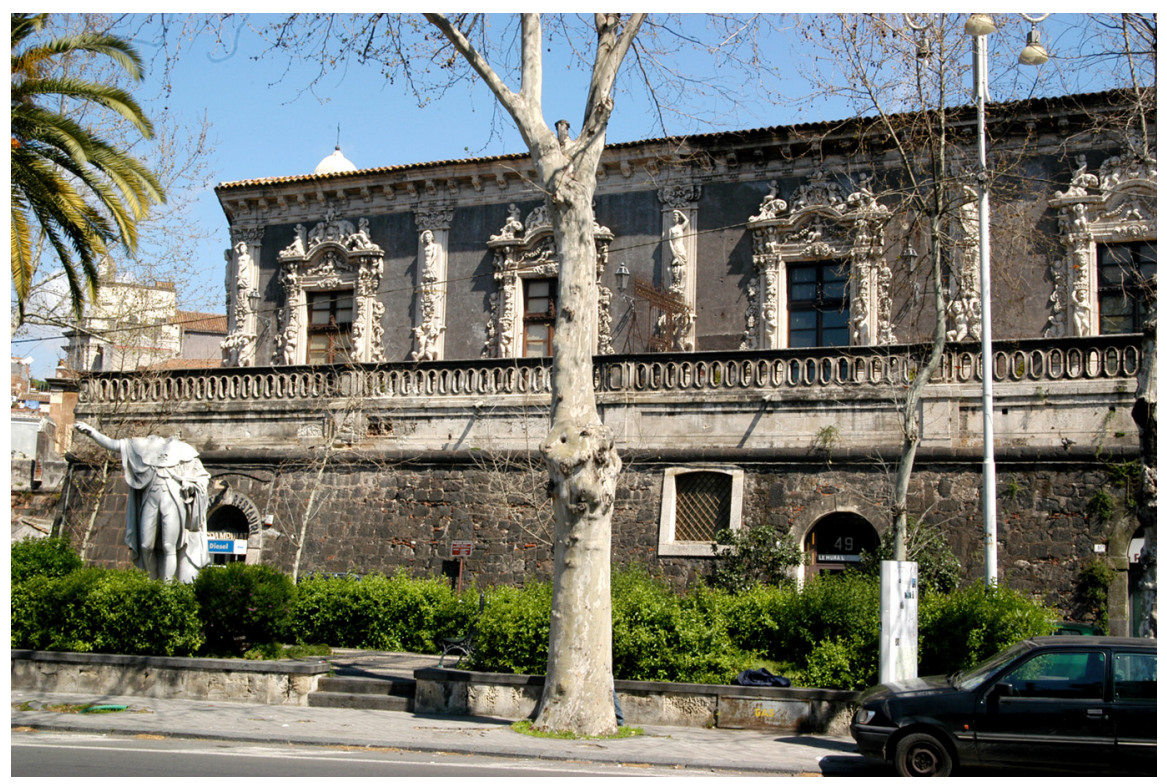

Fig. 1 Catania, Museum of Palazzo Biscari alla Marina, (photo authors).

purchased in 1904 for 1000 liras by Paolo Orsi from the Marquis of Castelluccio, who was another famous collector of antiquities. Due to the approximate context of provenance, the statue may have had funerary functions.

As separated artifacts, the two pieces were the subject of several studies aimed to define their style, chronology, and eventually, their provenance. In the light of more recent archaeometric analyses, they have reasonably been attributed to a Sicilian workshop influenced by the Attic-Ionic style, possible located in the area under the control of the Chalcidians, as Leontinoi was, and where raw blocks of marble regularly arrived from the Aegean. ${ }^{24}$ The closest comparisons that can be drawn for the head are the Rayet head of the Copenhagen Museum (Fig. 4), the kouros of Aristodikos from Attica (Fig. 5), and the so called Theseus of a group from the temple of Apollo at Eretria (Fig. 6), all of which range between 520 and $500 \mathrm{BC} .^{20}$

The first scholar who suggested a possible association between the head and the torso was Guido Libertini in the

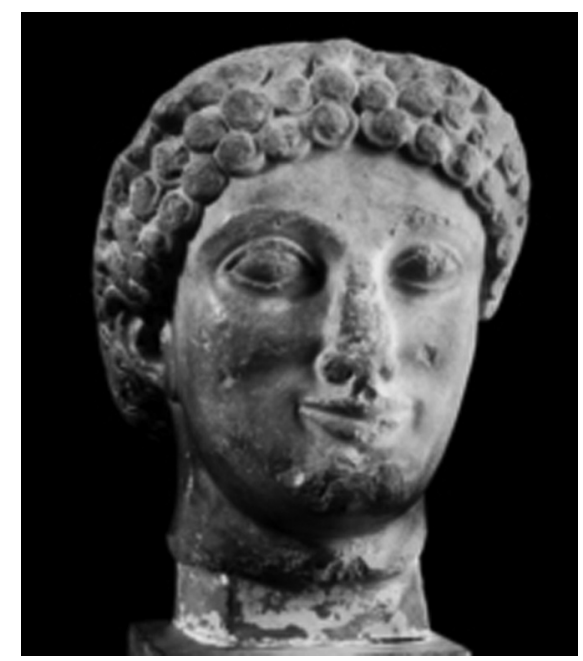

Fig. 2 The Biscari head (Archivio Fratelli Alinari, Firenze, 1938 ca.). 1930s. He produced a gypsum cast of the head in order to compare it with the torso to verify his hypothesis. Although a missing part of the neck did not allow for a perfect match, the volumetric correspondence together with the stylistic analogies was enough to support the idea that the two pieces

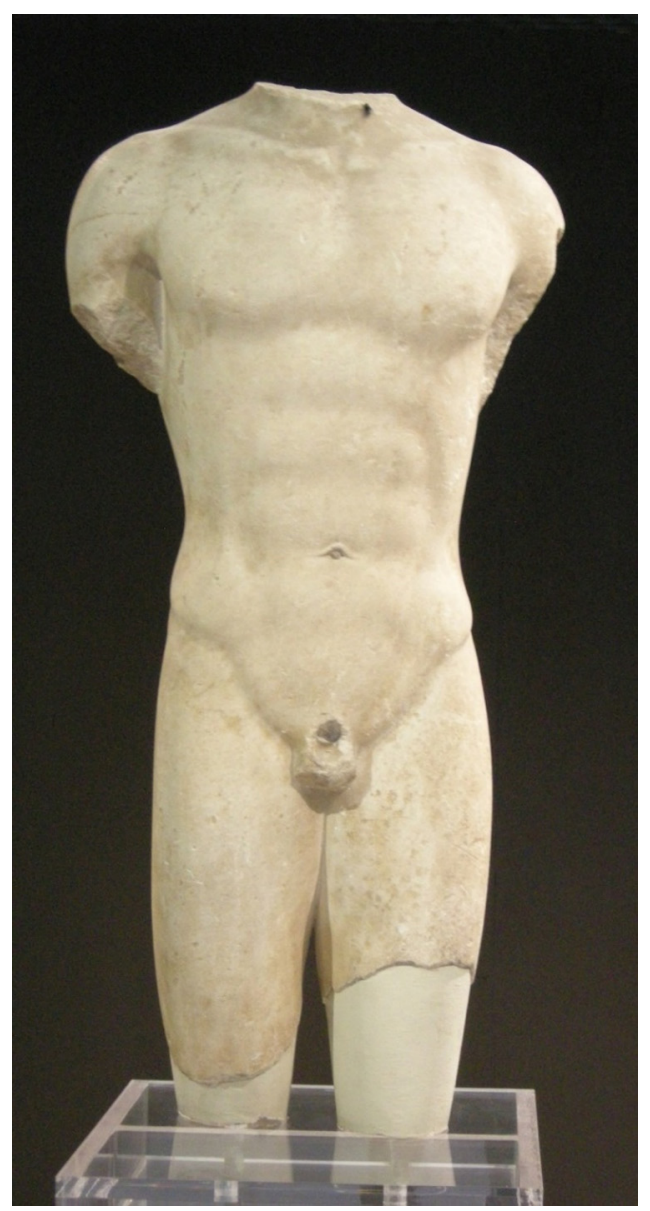

Fig. 3 The torso from Leontinoi (photo authors). 


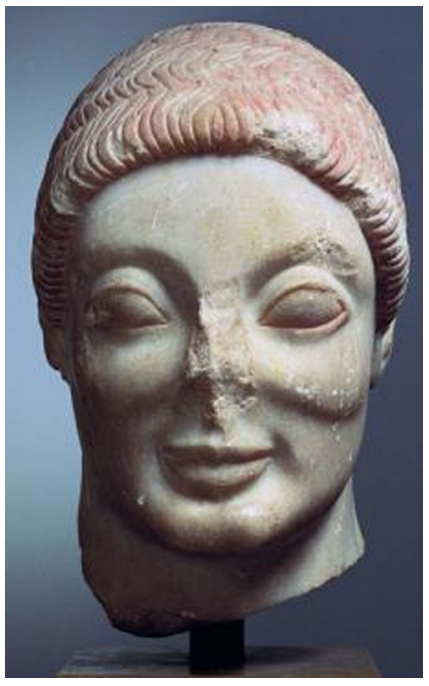

Fig. 4 The Rayet head. $^{25}$

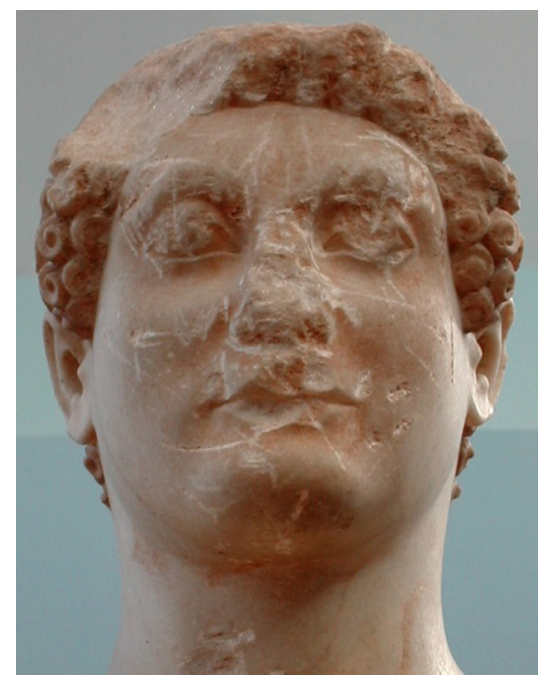

Fig. 5 The kouros of Aristodikos. ${ }^{26}$

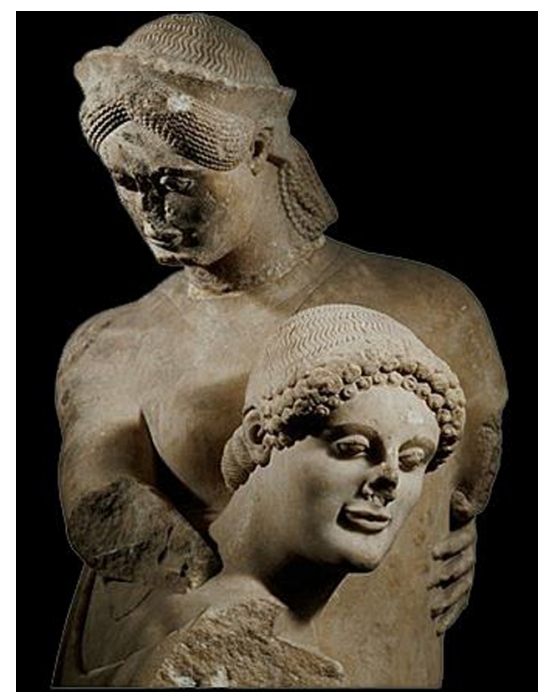

Fig. 6 The Group of Theseus and Antiope from the Temple of Apollo at Eretria. $^{27}$ were once a life-size kouros from Leontini. Unfortunately, no documentation has been recovered regarding this experiment.

Many decades later, Gino Vinicio Gentili reappraised the problem of the association of the two pieces using a photofit (Fig. 7), in which he matched the photographs of the head and the torso. ${ }^{28}$ This further confirmation of Libertini's hypothesis was published in a scientific paper with a very limited distribution. Again, the general public missed the remarkable discovery of the first intact Sicilian kouros.

In order to go beyond the exercises of Libertini and Gentile and to provide the final proof of the compatibility of the two pieces as part of the same statue, a reconstructive study has been carried out based on the 3-D scanning and virtual anastylosis of the kouros of Leontinoi.

\section{Virtual Anastylosis via Three-Dimensional Scanning}

\subsection{Virtual Anastylos}

"In recent years, virtual environments have been greeted positively by the public and scholars, testified by the quantity of thematic conferences on the subject of virtual archaeology.

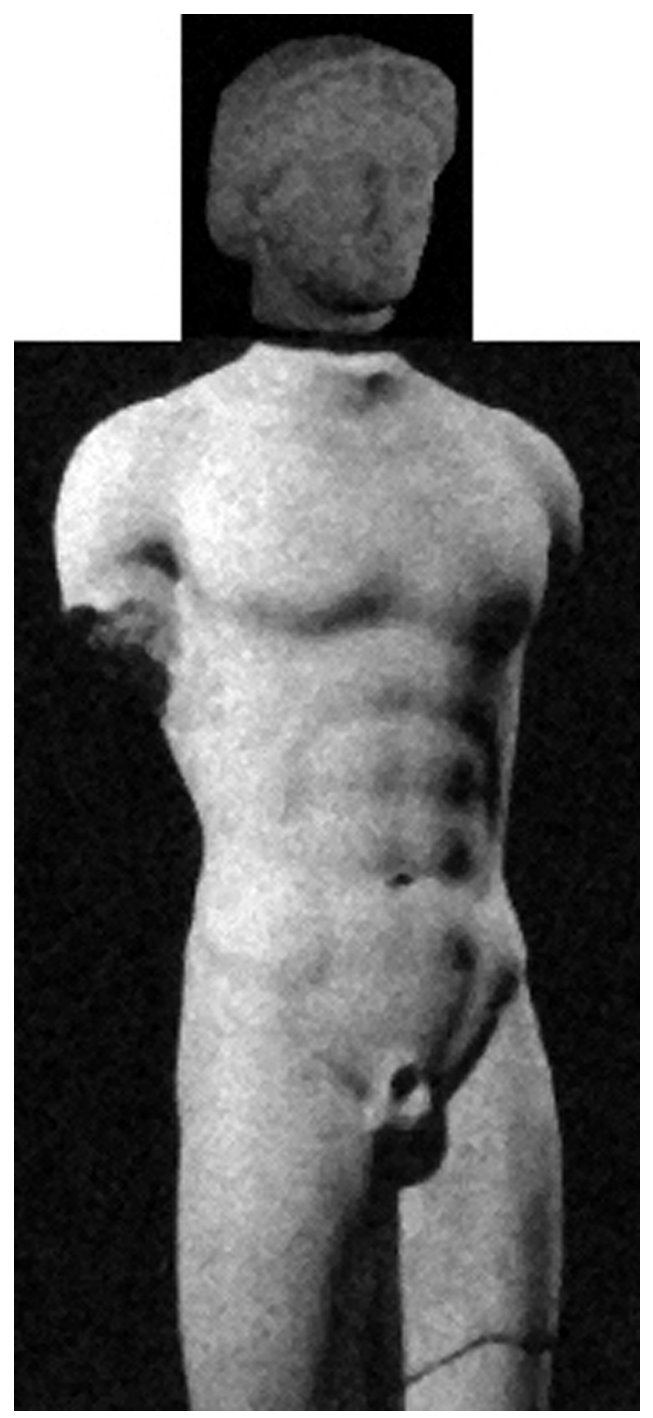

Fig. 7 Possible photofit of the head and the torso. 
Despite this, there are still many contradictions found in the varying terms and the diverse aims of the developing disciplines that gravitate around the field of virtual reality." 29

The publication of the London Charter in 2009 and of the Seville Principles in 2012 has contributed to the establishment of a shared set of guidelines for virtual archaeology for the scholarly community. In the preamble of the Seville Principles, a clear definition is provided for the first time of the terms "virtual restoration," "virtual anastylosis," "virtual reconstruction," and "virtual recreation" as four distinct separate moments of digital production. ${ }^{30}$ In particular, the concept of virtual anastylosis, i.e., the restructuring of existing but dismembered parts in a virtual model, is an interesting novelty that is applicable to a great number of archaeological case studies in which artifacts are often dismembered because of illegal excavations and international trafficking.

In this kind of research, 3-D scanning plays an important role. Due to the miniaturization and integration of electronic and optical components, 3-D scanners today are compact and are flexibly equipped with advanced Image Processing and Computer Vision algorithms guaranteeing satisfactory quality of digital 3-D geometry for many real applications in several fields. 3-D scanners are able to estimate depth measurements in order to acquire the geometrical surface of a real-world object and produce a 3-D digital version.

These devices can be classified into categories on the basis of their specific features. One feature concerns the emission of a signal to perform the acquisition. In this case, we can distinguish active scanners, which need to produce a particular electromagnetic signal for depth estimation, from passive scanners which are able to acquire the 3-D data without emitting any signal. Active scanners can be crafted employing different technologies as laser triangulation, structured light, time of flight, and interferometry. ${ }^{31}$

Passive scanners include: stereovision, which is based on the principle of reconstruction by stereo approach using two (or more) cameras that concurrently capture the same scene, photogrammetry, which is based on estimation of 3-D models from a set images and on the camera's calibration and orientation, and texture gradient, which is based on the analysis of the transformations of texture elements (texels) on the surface of the objects in order to estimate changes of orientation. ${ }^{32}$ In the last few years, many portable scanners have been developed, among them hand-held devices, which are small, fast, and relatively cheap. However, they are usually less accurate than fixed scanners due to different acquisition technology and hardware limitations.

\subsection{Structure Sensor}

Structure Sensor produced by Occipital ${ }^{33}$ (Fig. 8) is an active scanner that uses the structured light for 3-D estimation and is quite popular among archaeologists. ${ }^{34}$ Specifically, it projects an infrared grid of points whose deformation provides depth information. The scanner does not work well with sunlight due to solar radiation of infrared light that interferes with the grid pattern emitted by the scanner. Hence, it is preferable to use it in an indoor environment.

The device is designed for developers. Indeed, the manufacturer provides its own software development kit and maintains the library OpenNI 2. The scanner guarantees a maximum resolution of $1.0 \mathrm{~mm}$ and a maximum accuracy of $0.5 \mathrm{~mm}$. However, the accuracy critically decreases when

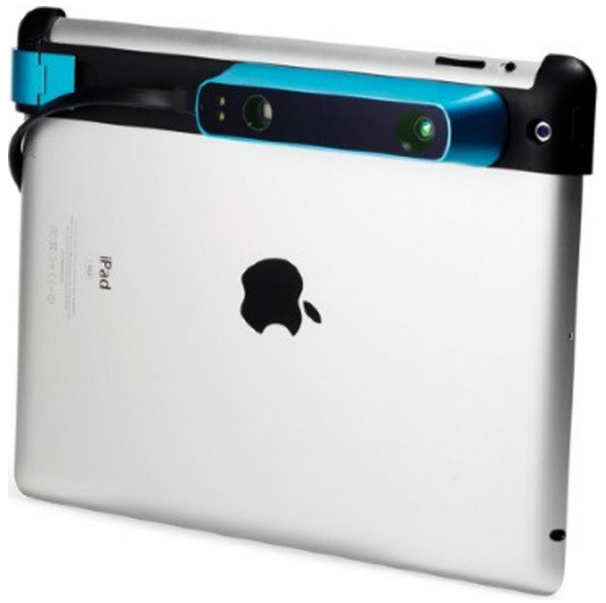

Fig. 8 Structure sensor clipped onto an iPad.

the distance between the sensor and the scanned object is increased. On the other hand, the resolution decreases when the volume of the object to be scanned increases. This device can run in three different modes. First, the device can be clipped on an iPad to exploit its hardware and software to acquire and export the 3-D mesh of the acquired object. Although this modality allows the maximum mobility, it has a big drawback, the acquired 3-D model can be exported through e-mail only and it is heavenly decimated. Hence, the exported model results in a low-resolution mesh. However, this obstacle can be bypassed by connecting the iPad to a common personal computer (PC) through adequate hardware and software. The link between the iPad and PC is established through a Wi-Fi connection and the software Skanect. It is important that both the Structure Sensor and the PC are connected to the same access point. In this mode, the Structure Sensor captures points and sends them in real time to the connected PC for processing and mesh creation. Greater hardware resources allow to perform higher quality scans, in other words, a higher number of vertices and the possibility to represent more mesh details. Specifically, in the case of head scanning, we obtained a 3-D model with 130,000 vertices through the PC and one with 60,000 through the iPad. Moreover, the mesh is directly stored in the PC.

Finally, the Structure Sensor can be directly connected to a PC USB port through a particular cable provided by the developers. This solution ensures a higher frame rate than a Wi-Fi network. The main problem with using Structure Sensor in this modality is related to texture acquisition. The device has no RGB camera; hence, if the operator decides to capture color information, it is mandatory to employ an iPad camera. This means that in the first and second modes only the texture can be acquired.

The Structure Sensor is relatively affordable and very fast. Moreover, user mobility is very high, allowing the operator to turn around the artifacts and scan them entirely in a single run. Acquisition details and other information on the case study will be provided in the following sections.

The hand-held scanner Structure Sensor has been employed to acquire 3-D models of two artifacts located in different museums: the head at Catania and the torso in Siracusa. Although the scanner is not able to represent fine 
details ( $\max 0.5 \mathrm{~mm}$ ), its resolution is high enough to perform a digital alignment of the scanned objects.

\subsection{Acquisition and Data Processing}

The acquisition was carried out with extreme care in order to properly capture the many anatomical details of the two pieces (Figs. 9 and 10). The scanning was performed using the Structure Sensor connected through Wi-Fi to Skanect in Uplink mode. The scan volume was set to $0.6 \mathrm{~m}^{3}$ for the head and to $1.2 \mathrm{~m}^{3}$ for the torso (Figs. 11 and 12).

Both artifacts were placed on a pedestal; in particular, the head was placed steadily on a metal support. After the 3-D capturing, 3-D models were manipulated with two popular software among archaeologists: Meshlab and Blender. Meshlab $^{35}$ was employed in order to refine the models in

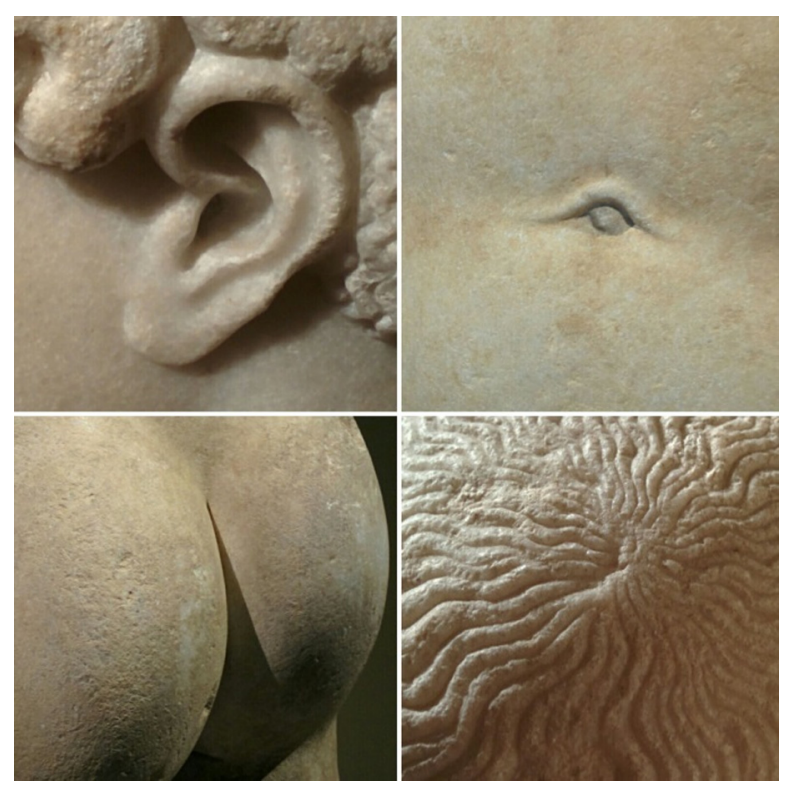

Fig. 9 Details of anatomical features of the head.

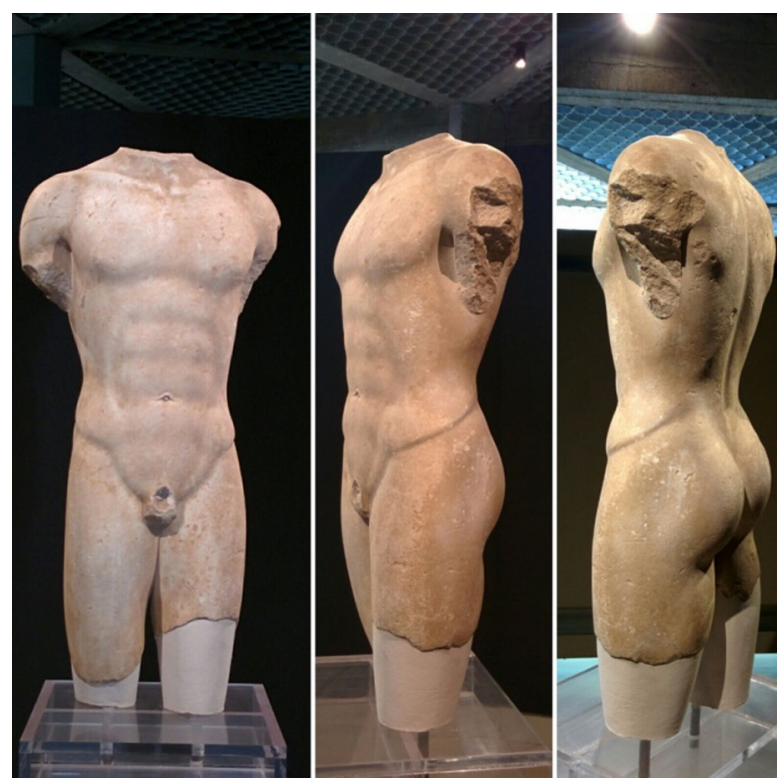

Fig. 10 Details of anatomical features of the torso. a preprocessing phase (Figs. 13 and 14): after digital acquisition, the vertices extraneous to the artifacts were deleted. The procedure was conducted in two steps. First, the following built-in automatic Meshlab functions were used: remove duplicate faces, remove duplicated vertex, remove zero area faces, remove isolated pieces (wrt Diameter, $\max =0.44$, value $=0.044$ ), and remove unreferenced vertex. Second, some residual noise was removed by carefully selecting it manually using the Meshlab built-in selection tool. Similarly, pedestals were cropped out. Finally, the final step was the gap filling through the close hole function (Figs. 15 and 16).

In Meshlab, it was possible to take digital measures of the head and the neck is order to verify an eventual dimensional compatibility. As shown in Figs. 17 and 18, dimensions of

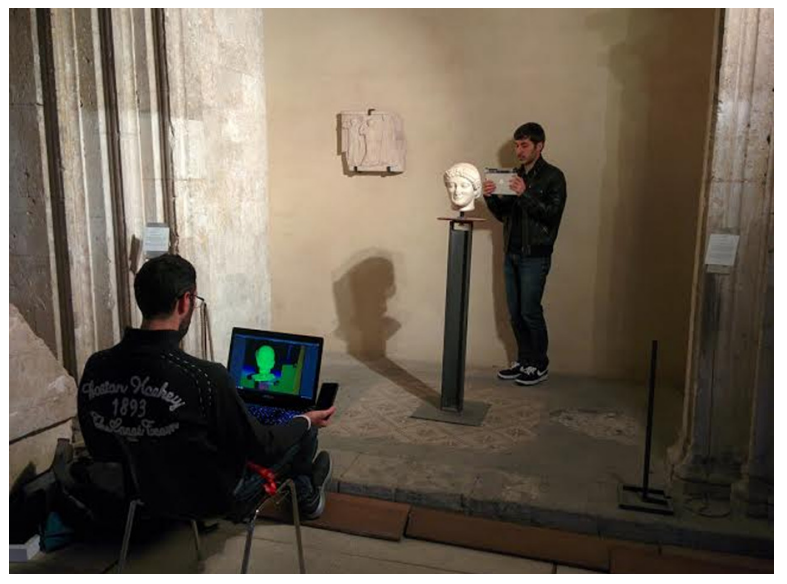

Fig. 11 Acquisition of the head at the museum of Catania.

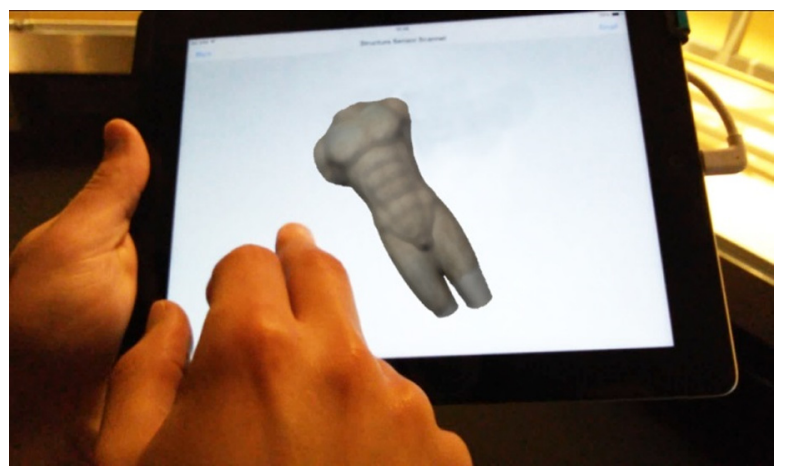

Fig. 12 Acquisition of the torso at the museum of Siracusa.

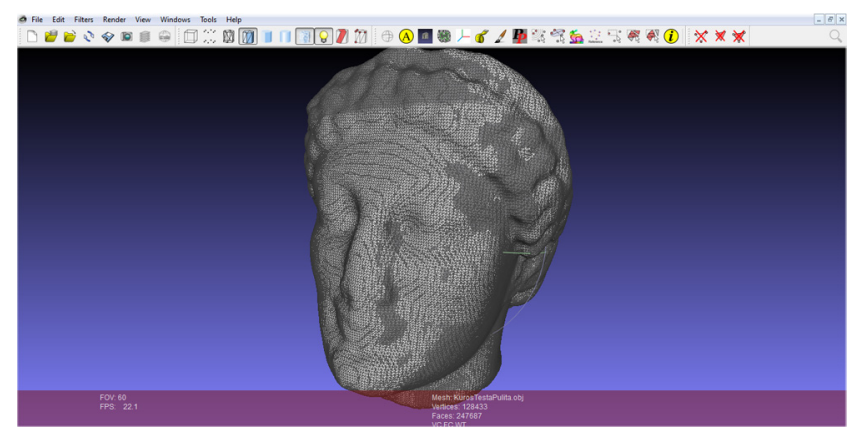

Fig. 13 Processing on the 3-D model of the head in Meshlab. 


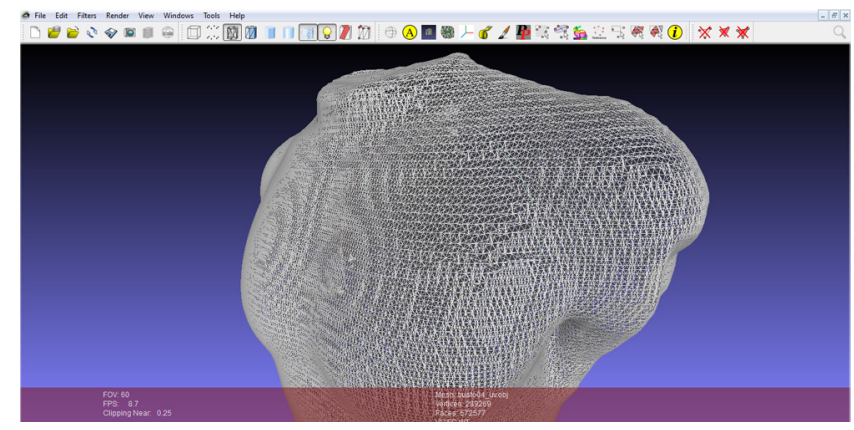

Fig. 14 Processing on the 3-D model of the torso in Meshlab.

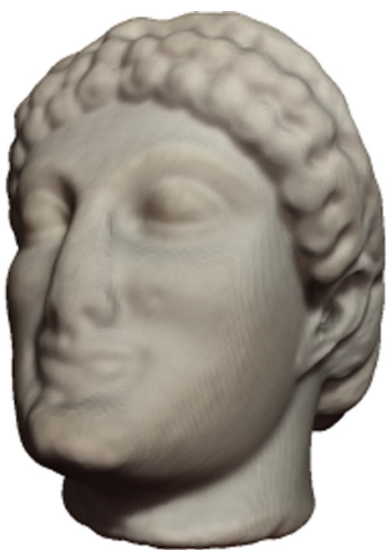

Fig. 15 Textured 3-D model of the head.

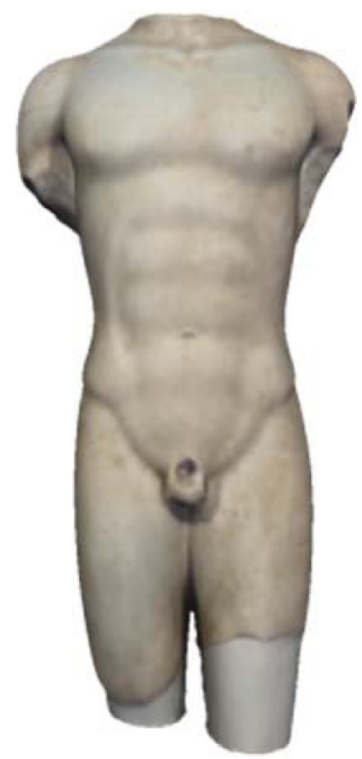

Fig. 16 Textured 3-D model of the torso.

the lower part of the neck of the head are $12.67 \times 13.67 \mathrm{~cm}$, while those of the upper part of the neck of the torso are $16.50 \times 13.27 \mathrm{~cm}$. Such dimensions, considering the possibility of physical decay of the edges, make dimensional compatibility between the two pieces likely.

Furthermore, when comparing the height of the head with that of the preserved torso (Fig. 19), it is clear that they are proportional to one another.

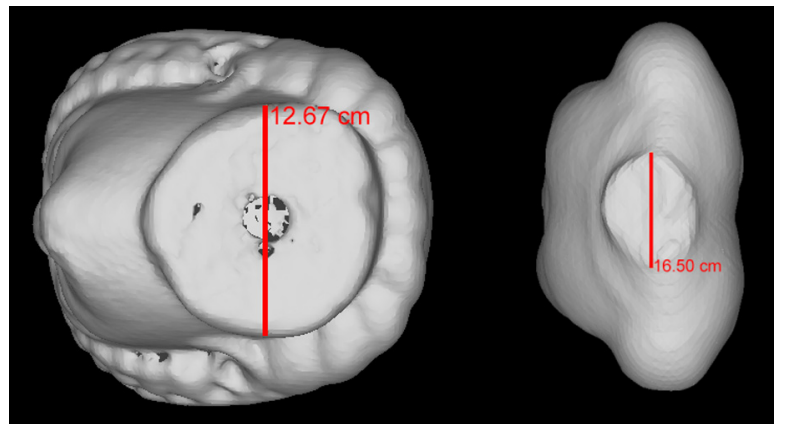

Fig. 17 Phases of digital measuring with Meshlab, diameters of head and torso.

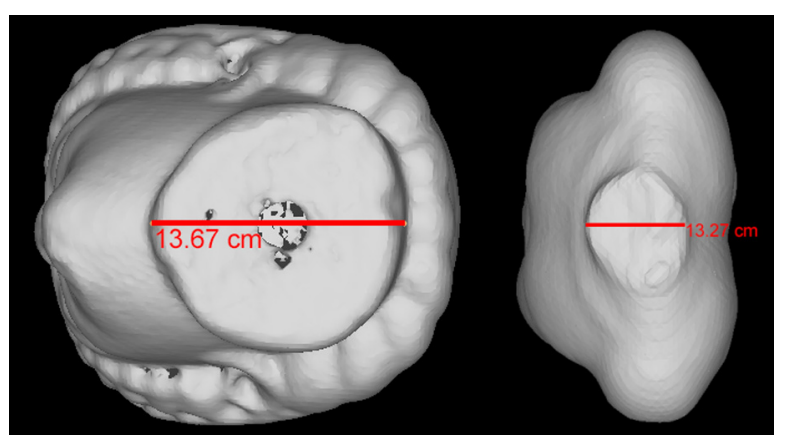

Fig. 18 Phases of digital measuring with Meshlab, other diameters of head and torso.

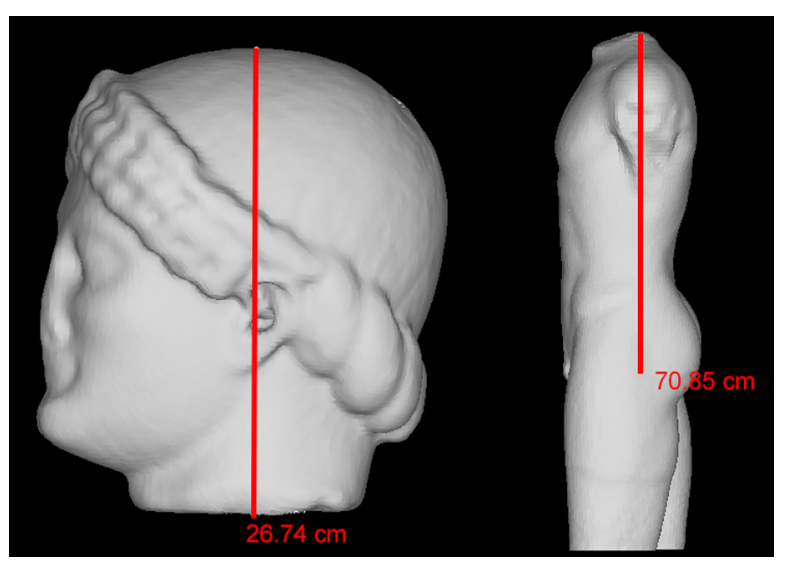

Fig. 19 Phases of digital measuring with Meshlab, heights of the pieces.

Subsequently the models were imported into Blender; ${ }^{36}$ in that environment, the head and torso of the kouros were manually aligned. Technical and archaeological analyses have shown that the statue misses part of the neck, as shown in the final result at Fig. 20.

\section{Sharing the Virtual Kouros of Leontini with the Public}

The research presented in this paper has clearly demonstrated that the hypothesis suggested in the first place by Libertini was correct. The two pieces are certainly part of the same statue, as they did not just share the same stylistic features, but they are also compatible in terms of geometry. The virtual 

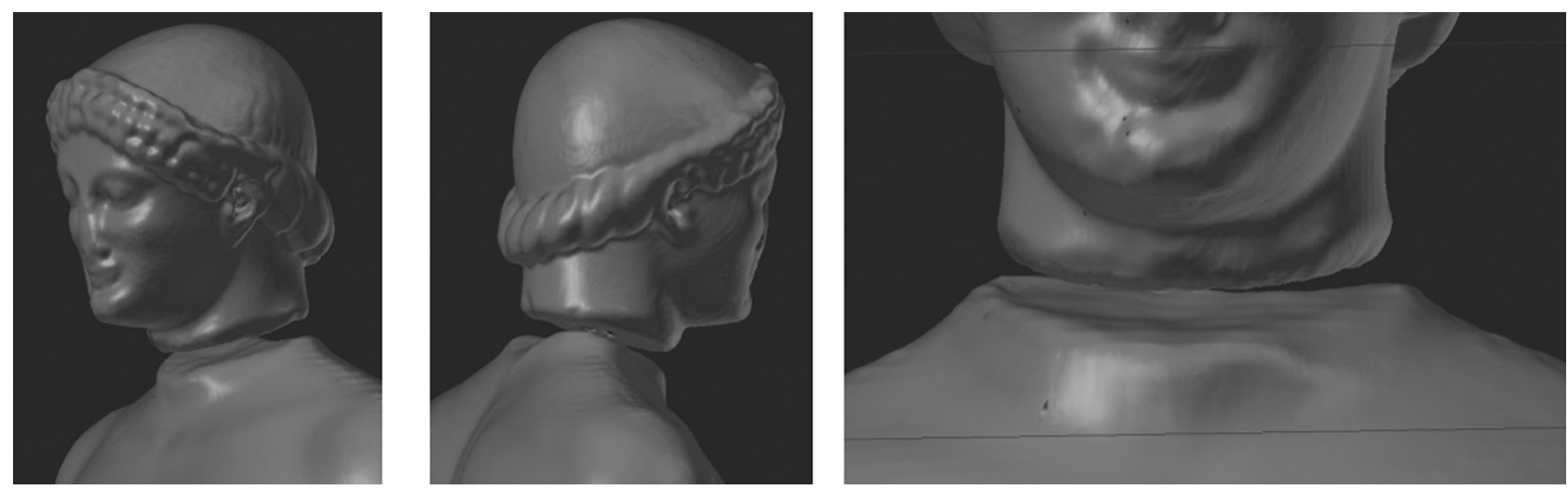

Fig. 20 Manual alignment of the 3-D models of the head and the torso in Blender.

anastylosis has, in fact, added a further level of information not previously present (Fig. 21). The statue seems very proportionate and the head, even in absence of a perfect match due to the lack of a segment of the neck, perfectly fits to the body.

A simple exercise of virtual anastylosis has given back to the community of scholars the first realistic representation of the kouros of Leontinoi, the first life-size statue of an Archaic kouros from Greek Sicily.

How would it be possible then to share with the public this remarkable discovery? How will the reputation of the two artifacts be improved by such a discovery?

Due to the strict management policies, neither of the two museums will surrender one of the pieces to the other in order to recombine the pieces and allow just one of the two institutions to have it in display. This suggests that the general public will never know about the kouros of Leontinoi and will never have the chance to see it in full.
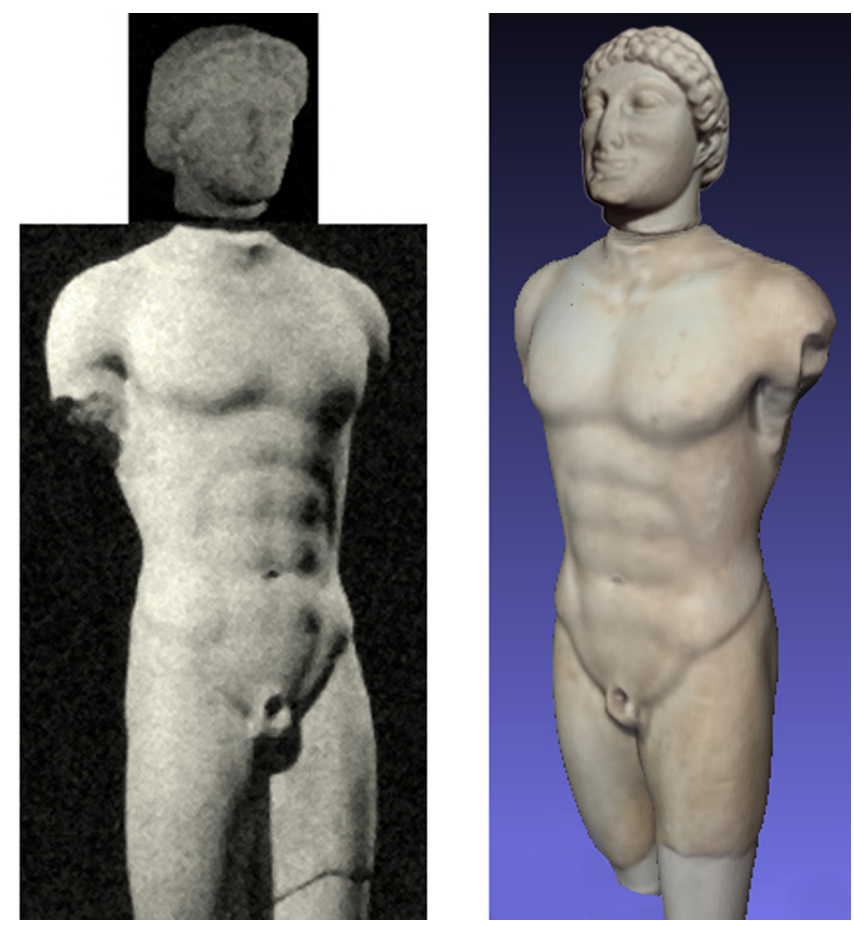

Fig. 21 Comparison between the photfit and the virtual anastylosis of the kouros of Leontinoi.
In response to this scenario, a web platform has been created on purpose in order to share in a simple and effective way the results of this research (Fig. 22). ${ }^{37}$

The main aim of this tool is to provide a proper and userfriendly visualization environment of the combined 3-D models, giving the opportunity to monitor the conditions of the artifacts ${ }^{38,39}$ and involve the community of World Wide Web users in the discussion. ${ }^{40-42}$ A prototype of the system has been developed with the Unity engine, version 5.0. Unity is a development platform with an integrated graphic game engine created by Unity Technologies. Unity is mainly used to produce videogames and entertainment products for different platforms, such as PCs, consoles, and mobile devices, and it allows for the management of 3-D models and other 3-D content, such as lights, pictures, and videos. Unity 5.0 has an integrated development environment, named Mono Develop, aimed to develop computer codes in two programming languages, JavaScript and C\#. The latter was used for the present work.

The user of the web platform will be able to interact with the 3-D model of the kouros of Leontinoi simply by using the mouse. The software provides two main views, Shaded and

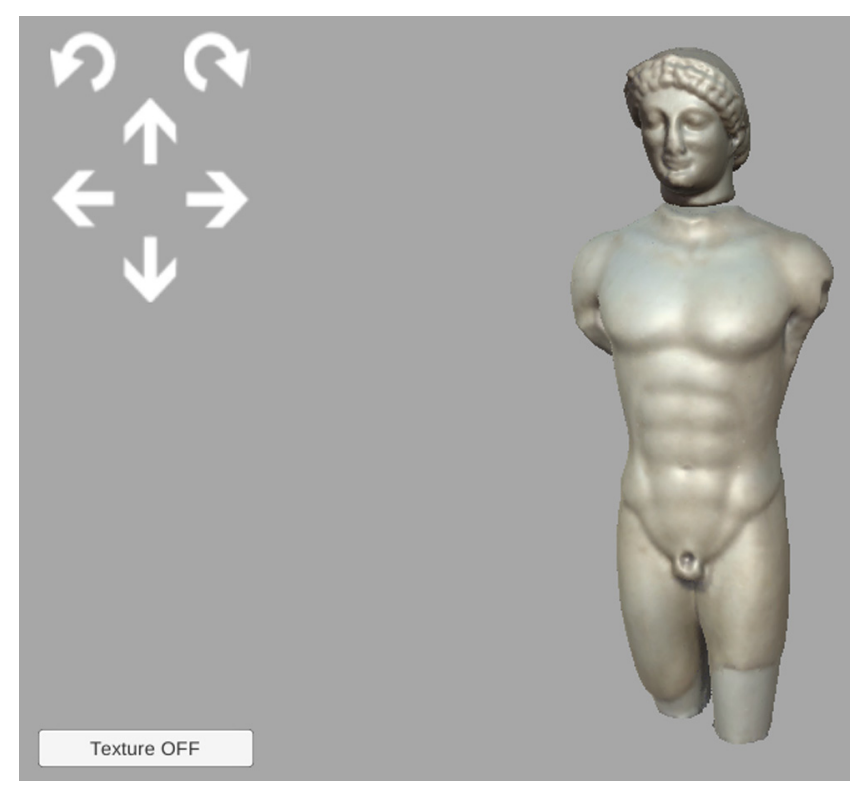

Fig. 22 Screenshot of the web platform for the virtual interaction with the kouros of Leontinoi. 
Textured. In the first view, the 3-D model will appear without material or texture and just the geometric data will be available in order to focus on the analysis of certain anatomical details, which can be obscured in the textured view (e.g., missing parts, gaps, and tools' marks).

\section{Learning by Objects}

\subsection{Three-Dimensional Printing}

As mentioned above, the possibility that the head and the torso will be recombined and that the kouros of Leontinoi will be displayed just in one museum seems quite remote, especially in the near future. The solution of sharing with the public the reassembled digital model on a web platform, certainly successful as a technical choice, unfortunately leaves out the learning process of people with visual impairments and cognitive disabilities.

Furthermore, as recent studies in neuroscience have pointed out, the lack of touch interaction for people without any kind of mental or physical disability can represent a cognitive limit, as "the relationship between touch and vision is perhaps most obvious when we ask to look something and immediately reach out with our hands to touch. Touch offers us much more than simply detecting the presence or absence of something ... it provides an understanding of the key properties of artifacts." 43

Therefore, the next step of our research effort was to create a physical copy of the statue in scale $1: 10$ through $3-\mathrm{D}$ printing (Figs. 23 and 24).

After final processing and digital corrections, the 3-D model was converted to .STL format and sent to the printer after slicing. The model of the statue was fabricated on a highly customized Delta robot-type Fused Deposition Modeling 3-D printer at the University of South Florida Labs. For enhanced part accuracy, the effector of this machine is held in place using a low-friction magnetic suspension system. The positioning accuracy of this delta robot is better than $50 \mu \mathrm{m}$ in the $x$-, $y$-, and $z$-directions.

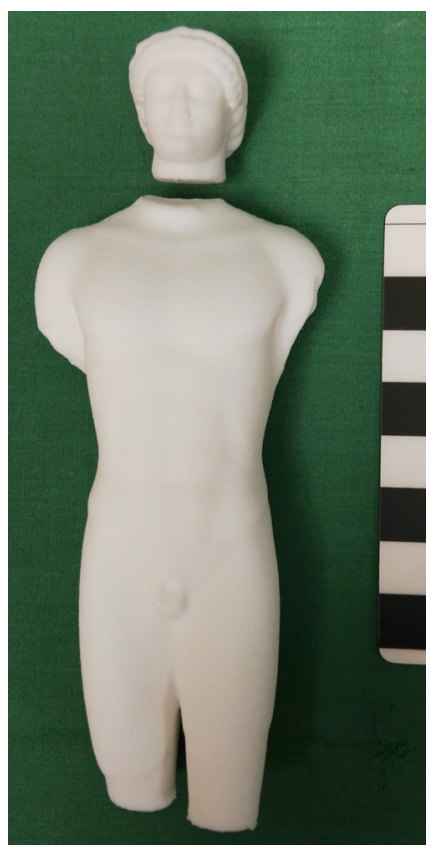

Fig. 23 3-D print of the head and the torso.

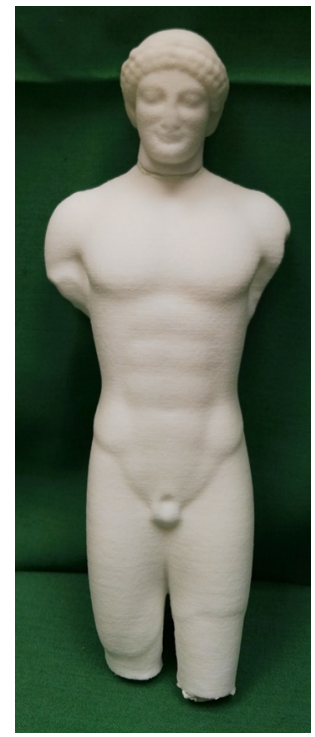

Fig. 24 Reassembled replica of the kouros of Leontinoi.

A low-force optically triggered $z$-probe was used to calibrate the build plate surface prior to printing to enhance print reliability and adhesion. The printing material selected was white polylactic acid, which was extruded at a temperature of $205^{\circ} \mathrm{C}$. This particular polymer was selected due to its ability to resist warpage and shrinkage, which might cause layer delamination on an object of this size. To further minimize warpage, the build plate, made of glass with waterbased acrylic glue adhesion promotor, was heated to $55^{\circ} \mathrm{C}$. Ambient conditions during printing were $26^{\circ} \mathrm{C}$, humidity $52 \%$ to $60 \%$. Slicing layer height was set to $0.15 \mathrm{~mm}$ $(150 \mu \mathrm{m})$ with a relatively low $12 \%$ part fill density. An extrusion nozzle of $0.4 \mathrm{~mm}$ in diameter was used. Mechanical supports were enabled to ensure that printing of overhanging and highly sloped geometry would be successful. Total print time was $\sim 24 \mathrm{~h}$ and consumed $\sim 170 \mathrm{~g}$ of polymer. Postprint work-up was kept to a minimum and included the mechanical removal of the support structures and spot smoothing with a hot air rework tool. The physical model is not hollow, but fully solid in order to increase its weight for a more accurate and realistic final result.

To touch a sixth century BC statue or to hold its polymeric replica do not evoke the same emotions, but the opportunity to hold the replica without fear of dropping it, damaging it, manipulating it, or using it for its intended purpose, makes it more "authentic." In fact, "the experiences elicited by touch in this context go beyond, but do not exclude, learning and enjoyment to include deep emotional responses stimulated by object handling." 44

Although conservation and preservation remains among the top priorities for most museums, the need for the audience to see, touch, and to feel the object of their interest must not be underestimated. In addition, it must be considered that "people now inhabit a multimedia world, with all the expectations that this brings and that museums need to become familiar with the languages of these technologies to stay relevant." ${ }^{, 5}$

\subsection{Haptic Technology}

The choice to 3-D print in scale and physically reassembly the statue would certainly be a good way for the curators of 


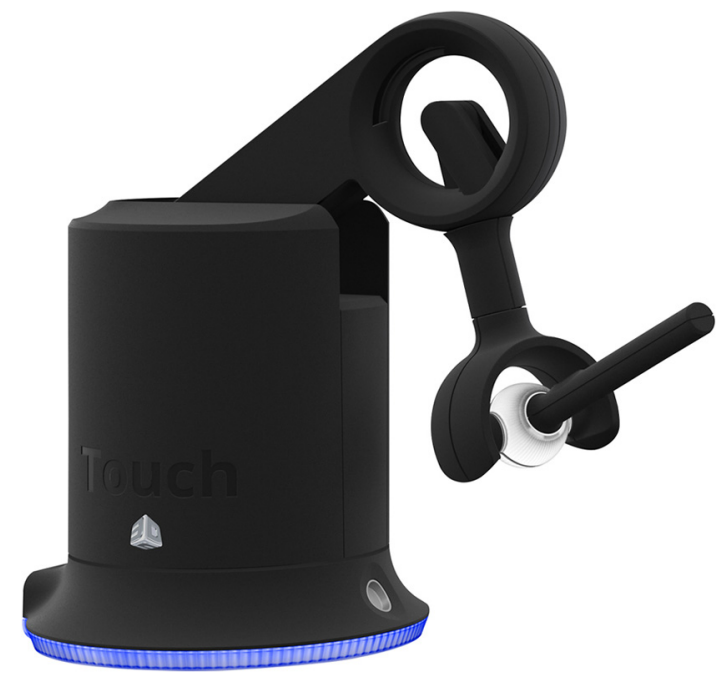

Fig. 25 3-D Systems Touch 3-D stylus.

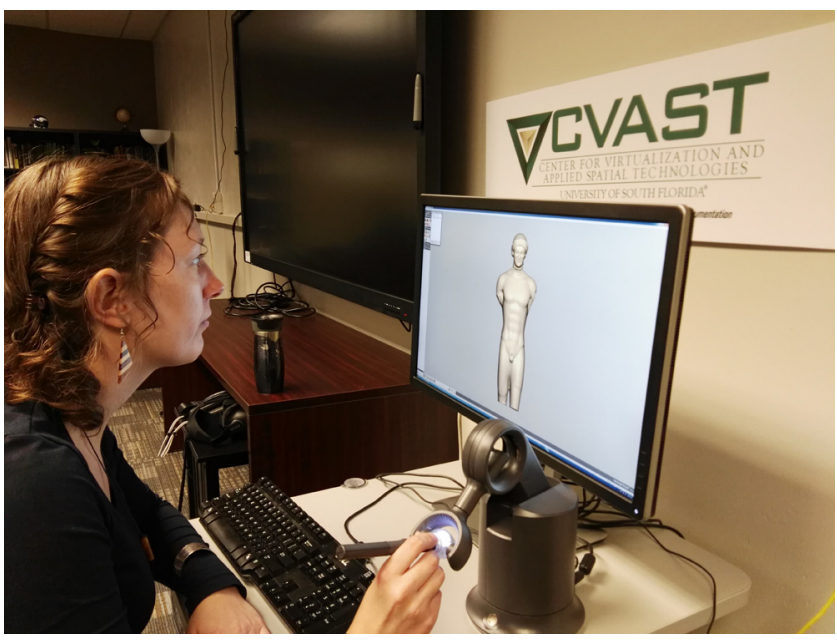

Fig. 26 Touch interaction with the digital model of the statue through haptic technology. both the museums of Catania and Siracusa to showcase how this unique example of Greek sculpture looked. Furthermore, in the case of the archaeological museum of Siracusa, where there is already a tactile collection of artifacts ranging from Prehistory to the Greek period, the replica of the kouros of Leontini will represent another example of enhanced realization for the public with visual impairments.

However, the process of 3-D printing is still rather time consuming and expensive, especially for models of medium to larger sizes and with other materials than simple polymers. In this respect, at this stage, it cannot be the only solution to make archaeological objects immediately more accessible and let visitors with or without cognitive deficits learn from touching the subject of their interest.

Promising results come from the recent research on haptic technologies applied to museum studies and may be able to offer an alternative perspective on this issue and show a new way of learning through objects. ${ }^{44}$

In order to validate the sensorial experience of interacting with the 3-D model of the reassembled statue and to compare it with the direct touch interaction with 3-D print of the statue in 1:10 scale, an experimental test has been undertaken at the Center for Virtualization and Applied Spatial Technologies $\left(\mathrm{CVAST}^{46}\right)$ of the University of South Florida. Using the haptic device 3-D Systems Touch 3-D stylus (Fig. 25) paired with the proprietary software Geomagic Sculpt, a group of students were asked to interact with the digital model (Fig. 26), and then to interact with the 3-D print, and finally describe the feedback in a questionnaire (Table 1) inspired by the questionnaire designed for the experiment with the bronze bust of Sophocles at Northlight Gallery of Huddersfield in 2006. ${ }^{11}$

The results achieved with a preliminary test employing a very limited sample of students clearly highlight the importance of any kind of touch interaction as a crucial step toward a more in-depth learning process. The other significant outcome is how the haptic device makes the interaction with the digital models more genuine and intense. Unfortunately, at this stage of the research, it has not been possible to extend the experiment to a larger sample including students with visual impairments and cognitive disabilities, leaving room for a further step in the research agenda.

Table 1 Questionnaire used to validate the touch interaction with the 3-D print and the sensorial experience with the haptic device.

\begin{tabular}{llllll}
\hline & & & & \\
D & SD & A & SA
\end{tabular}

Interpreting the museum objects through virtual or real tactile experience is a very inclusive approach

I felt that the touch interaction provided space to add my own interpretation

I felt more genuine the touch interaction with the 3-D print than that with through the haptic device

With the help of the haptic device, the computer interface seemed to vanish

After interacting either with the 3-D print and the digital models via the haptic device, I felt I interacted directly with the statue

Note: $\mathrm{SD}=$ strongly disagree, $\mathrm{D}=$ disagree, $\mathrm{U}=$ undecided, $\mathrm{A}=$ agree, and $\mathrm{SA}=$ strongly agree. 


\section{Future Works}

The first item in the research agenda is the implementation of the questionnaire integrating in it the remarks and suggestions provided during the first round of interviews. Subsequently working with the Office for Diversity, Inclusion, and Equal Opportunity of the University of South Florida, ${ }^{47}$ a more ample group of interviewees will be put together, including students with visual impairments and cognitive disabilities in order to gather more clear data about the relevance of the use of haptic technologies and 3-D printed casts in the learning process of archaeology. This next phase of the research will be carried out at CVAST using six 3-D Systems Touch 3-D Stylus devices and related Geomagic Sculpt licensed software. Four further 3-D casts of the statue will be printed out using different materials than acrylic plastic, namely gypsum, porcelain, metallic plastic, aluminum, and a fifth will be printed out with the same acrylic plastic, but in contrast to the first, it will be hollow inside. These various materials will be tested in order to ascertain whether the different materials, textures, and weights could or could not have an impact on the sensorial and cognitive experience. The results of the survey will be compared with other similar exercises where different other multimodal approaches were also involved. ${ }^{48}$

This research has elucidated how 3-D scanning, virtual anastylosis, and web sharing can contribute to the improvement of museum policies in the field of public outreach, showing how a case of limited accessibility, represented by the state of a Greek statue irremediably divided in pieces between two museums, can become the public's path to virtual discovery of a new masterpiece of Greek sculpture.

Furthermore, the employment of 3-D printing and haptic technology has demonstrated the strategic importance of touch interaction in the learning process of archaeology not just for the public with visual or mental impairments, but it has pointed out an alternative way to enhance the access to the cognitive process itself.

\section{References}

1. D. M. Seekins, "State, society and natural disaster: cyclone Nargis in Myanmar (Burma)," Asian J. Social Sci. 37(5), 717-737 (2009).

2. J. Curtis, "Archaeology and cultural heritage in war zones, in: history for the taking? Perspectives on material heritage," The British Academy, pp. 55-75, London (2011).

3. I. Vinson, Ed., "Return and restitution of cultural objects: the Athens conference," in MUSEUM International N²41-2, UNESCO (2009).

4. T. Cevoli, "La Venere di Cirene e gli accordi per la restituzione dall'Italia alla Libia," Archeomafie 3, 11-34 (2011).

5. A. Harding, "The problem of illicit antiquities: an ethical dilemma for scholars," in History for the Taking? Perspectives on Material Heritage, British Academy Report, pp. 77-109 (2011).

6. "Report of the Italian ONG Lega Ambiente," http://www.legambiente.it/ temi/ecomafia/archeomafia (27 December 2016).

7. A. Addison, "The vanishing virtual: safeguarding heritage's endangered digital record," in New Heritage: New Media and Cultural Heritage, Y. Kalay, T. Kvan, and J. Affleck, Eds., pp. 27-39, Routledge, London (2007).

8. S. Hermon and L. Kalisperis, "Between the real and the virtual: 3D visualization in the cultural heritage domain-expectations and prospects,' in Arqueologica 2.0, Proc. of 1st Int. Meeting on Graphic Archaeology and Informatics, Cultural Heritage and Innovation, pp. 99-103 (2009).

9. M. Mc Linden and S. McCall, Learning Through Touch: Supporting Children with Visual Impairment and Additional Difficulties, David Fulton, London (2002).

10. R. Zimmer, J. Jefferies, and M. Srinivasan, "Touch technologies and museum access," in Touch in Museums: Policy and Practice in Object Handling, H. J. Chatterjee, Ed., pp. 150-162, Berg, Oxford (2008).

11. I. Onol, "Tactual explorations: a tactile interpretation of a museum exhibit through tactile art works and augmented reality," in Touch in Museums: Policy and Practice in Object Handling, H. J. Chatterjee, Ed., pp. 91-106, Berg, Oxford (2008).
12. C. Jiménez Hurtado, C. Seibel, and S. Soler Gallego, "Museums for all: translation and interpreting for multimodal spaces as a tool for universal accessibility," in MonTI 4trans, pp. 1-24, Universitat d'Alacant, San Vicente del Raspeig (Alicante) (2012).

13. F. Gabellone, "La fruizione di dati archeometrici e prospezioni geofisiche in ambienti virtuali," in Open Source, Free Software e Open Format nei processi di ricerca archeologica, Proc. of the 8th ARCHEOFOSS Conf., pp. 220-229, Archeopress, Catania (2016).

14. K. Garstki, "Virtual representation: the production of 3D digital artifacts," J. Archaeolog. Meth. Theo., 1-25 (2016).

15. M. A. Otaduy, A. Okamura, and S. Subramanian, "Haptic technologies for direct touch in virtual reality," in ACM SIGGRAPH 2016 Courses, p. 13 (2016).

16. R. Pierdicca et al., "Making visible the invisible: augmented reality visualization for 3D reconstructions of archaeological sites," in Augmented and Virtual Reality, Proc. of the Second Int. Conf., pp. 25-37, AVR, Lecce, Italy (2015).

17. G. M. A. Richter, Kouroi Archaic Greek Youths: A Study of the Development of the Kouros Type in Greek Sculpture, Phaidon Press, London (1960).

18. A. Anderson, Beauty and Truth, Agora, Boston (2007).

19. E. De Miro, "La scultura siceliota in Sicilia nell'età classica," in I Greci in Occidente. Catalogo, II edizione, G. Pugliese Carratelli, Ed., Bompiani Milano (1996).

20. R. Panvini and L. Sole, Eds., La Sicilia in età arcaica. Dalle apoikiai al 480 a.C., Regione Siciliana, Assessorato dei Beni Culturali, Ambientali e della Pubblica Istruzione, Palermo (2009).

21. S. Pafumi, Le antichità del principe di Biscari: scelte e criteri espositivi di un collezionista tra antiquaria e nuova scienza archeologica, in Oggetti, uomini, idee, pp. 87-116, Pisa, Roma (2009).

22. G. Libertini, Il Museo Biscari, Casa editrice d'arte Bestetti e Tumminelli, Roma (1930).

23. G. Libertini, Il Castello Ursino e le raccolte artistiche comunali di Catania, Zuccarello \& Izzi, Catania (1937).

24. B. Basile and L. Lazzarini, "The archaeometric identification of the marbles of the Greek statuary and architectural elements of the "Paolo Orsi" Museum in Syracusein," Marmora 8, 11-32 (2012).

25. Museum of Classical Archaeology Databases: Rayet Head, University of Cambridge, http://museum.classics.cam.ac.uk/collections/casts/ rayet-head (27 December 2016).

26. Ancient-Greece.org, Aristodikos Kouros, http://ancient-greece.org/ images/art/kouros/pages/14aristodikos_jpg.htm (27 December 2016).

27. Museum of Classical Archaeology Databases: Theseus and Antiope, University of Cambridge, http://museum.classics.cam.ac.uk/collections/ casts/theseus-and-antiope (27 December 2016).

28. G. V. Gentili, "I due kouroi da Osimo e i tre kouroi del vecchio museo Archeologico di Siracusa nello studio e ricordo di Luigi Bernabò Brea," in In memoria di Luigi Bernabò Brea, M. Cavalier and M. Bernabò Brea, Eds., pp. 67-106, M. Grispo, Palermo (2002).

29. F. Gabellone, "Digital technologies and communication: prospects and expectations," Open Archaeol. 1, 102-118 (2015).

30. V. M. Lopez-Menchero and A. Grande, "The principles of the Seville Charter, CIPA,' http://cipa.icomos.org/fileadmin/template/doc/PRAGUE/ 096.pdf (2011).

31. G. Guidi, "Terrestrial optical active sensors- theory \& applications," in $3 D$ Recording and Modelling in Archaeology and Cultural Heritage: Theory and Best Practices, S. Campana and F. Remondino, Eds., pp. 39-64, Bar International Series, Vol. 2598, ArchaeoPress, Oxford, United Kingdom (2015).

32. W. Linder, Digital Photogrammetry, Springer, Springer-Verlag Berlin Heidelberg (2016).

33. "3D scanning, augmented reality, and more for mobile devices," Structure.io, http://structure.io (27 December 2016).

34. A. Barmpoutis, E. Bozia, and D. Fortuna, "Interactive 3D digitization, retrieval, and analysis of ancient sculptures, using infrared depth sensors for mobile devices," in Proc. of the 9th Int. Conf. on Universal Access in Human-Computer Interaction. Access to the Human Environment and Culture, Lecture Notes in Computer Science, Vol. 9178, pp. 3-11 (2015).

35. P. Cignoni et al., "MeshLab: an open-source mesh processing tool," in Proc. of Eurographics Italian Chapter Conf., pp. 1-8 (2008).

36. F. Delli Ponti et al., "A blender open pipeline for a 3D animated historical short film," in Proc. of the 12th Int. Symp. on Virtual Reality, Archaeology and Cultural Heritage, pp. 81-90, VAST, The Eurographics Association, Goslar, Germany (2011).

37. Virtual restoration of Greek sculpture as museum policy for public outreach and cognitive accessibility, University of Catania, http://yoda.dmi. unict.it/kouros/ (27 December 2016).

38. G. Marchand et al., "Degradation of archaeological horn silver artefacts in burials," Heritage Sci. 2(5), 1-7 (2014).

39. F. Stanco et al., "Augmented perception of the past: the case of Hellenistic Syracuse," J. Multimedia 7(2), 211-216 (2012).

40. F. Stanco and D. Tanasi, "Beyond virtual replicas: 3D modeling and Maltese prehistoric architecture," J. Electron. Comput. Eng. 2013, 1-7 (2013). 
41. D. Allegra et al., "Un approccio multidisciplinare per lo studio di un tesoro unico al mondo. Gli argenti della casa di Eupolemo a Morgantina," in Morgantina duemilaequindici. La ricerca archeologica a sessant'anni dall'avvio degli scavi Regione Siciliana, Palermo (2015).

42. F. Stanco et al., "Augmented perception of the past: the case of the telamon from the Greek theater of Syracuse," Proc. of the Int. Workshop on Multimedia for Cultural Heritage (MM4CH 2011), pp. 126-135, Springer-Verlag, Berlin/Heidelberg (2012).

43. R. Doonan and M. Boyd, "CONTACT: digital modelling of object and process in artefact teaching," in Touch in Museums: Policy and Practice in Object Handling, H. J. Chatterjee, Ed., pp. 107-120, Berg, Oxford (2008).

44. H. J. Chatterjee, Ed., Touch in Museums: Policy and Practice in Object Handling, Berg, Oxford (2008).

45. D. Romanek and B. Lynch, "Touch and the value of object handling: final conclusion," in Touch in Museums: Policy and Practice in Object Handling, H. J. Chatterjee, Ed., pp. 275-286, Berg, Oxford (2008).

46. Center for virtualization and applied spatial technologies, Homepage, https://cvast.usf.edu/ (27 December 2016).

47. Center for virtualization and applied spatial technologies, Diversity, inclusion \& equal opportunity, https://cvast.usf.edu/ (27 December 2016).

48. P. D. G. Di Franco et al., "3D printing and immersive visualization for improved perception of ancient artifacts," Presence 24(3), 243-264 (2015).

Filippo Stanco is an associate professor in the Department of Mathematics and Computer Science of the University of Catania. $\mathrm{He}$ is the coordinator of the "Archeomatica project" to develop new digital tools for archaeological research and the preservation of cultural heritage. His research interests also include digital restoration, zooming, superresolution, artifacts removal, interpolation, texture, and geographic information system. He has published hundreds of papers in international journals and proceedings of conferences in those fields.

Davide Tanasi is an assistant professor at the CVAST and the Department of History of University of South Florida. His research interests include the archaeology of ancient Sicily, computer graphics in archaeology, and cultural heritage. He has authored a hundred scientific papers in these fields and produced 3-D documentaries about sicilian archaeology and cultural heritage. Since 2013 he has been editor of the international scientific journal Open Archaeology.

Dario Allegra received his bachelor's degree in computer science (summa cum laude) in 2012 and his master's degree (summa cum laude) in 2014 from the University of Catania. He is a PhD student in the Department of Mathematics and Computer Science, University of Catania. His research interests are image processing, multimedia, and pattern recognition.

Filippo Luigi Maria Milotta received his bachelor degree in computer science (summa cum laude) in 2012 and his master degree (summa cum laude) in 2014 from the University of Catania. Currently, he is a $\mathrm{PhD}$ candidate with grant by Telecom Italia in "multidevice video analysis and summarization for high bandwidth connected environments." His research interests include image processing, multimedia, and multidevice systems.

Gioconda Lamagna former archaeologist officer with the Superintendence of Catania, has supervised several excavations in the Simeto valley and in the Caltagirone area. Since 2010, she has being director of prominent archaeological parks and museum in Sicily as the Parco archeologico della Valle del Simeto (2010-2013), the Museo Archeologico Regionale "Paolo Orsi" di Siracusa (2013-2016), and the Polo regionale di Agrigento per i siti culturali - Museo Archeologico Regionale "Pietro Griffo" (2016 - present).

Giuseppina Monterosso is a specialist of classical archaeology. Since 2005, she is archaeologist officer with Museo Archeologico Regionale "Paolo Orsi" di Siracusa, where she has supervised the project PO-FESR 2007-2013 "Vedere, Sentire, capire. Adeguamento tecnologico dell'apparato didattico del Museo Archeologico Regionale Paolo Orsi - Siracusa". Her scientific interests include problems of production and circulation Corinthian pottery and architectural terrecottae from Greek Sicily. 